\title{
Risk Management Behaviors of Wilderness Outfitters and Guides in North America
}

\author{
Gary R. Gray \\ Iowa State University
}

\section{INTRODUCTION}

Each year millions of active Americans and Canadians leave their city surroundings and flock to wilderness environments in an attempt to "get away from it all." Hiking, camping, canoeing, kayaking, rafting, and cross-country skiing are just a few of the vigorous outdoor pursuits that individuals enjoy amidst the beauty of nature. Although many of these recreationists purchase their own outdoor gear and head for the wilderness on a regular basis, many participants choose to rent their equipment from a professional outfitter. Likewise, many individuals strike out on their own in either familiar or unfamiliar surroundings while others choose to pay for the services of a professional guide.

Wilderness outfitting and guiding is an entire industry in North America which caters to providing for the equipment and/or leadership needs of outdoor enthusiasts. The services that are available are indeed diverse, and essentially almost any type of outfitting and/or guiding request can be accommodated. One person might desire to rent a canoe for an hour while someone else might prefer to spend a week white-water rafting down a western river, complete with all equipment, food, and leadership provided. Most outfitters and guides seem very willing to design their services to meet the needs of individual clients.

Foremost among the many concerns that outfitters and guides have for their clients is that of safety. Certainly nobody wants to spend his or her long-awaited vacation in the emergency room of a hospital as the result of a broken leg. Related to safety, but beyond the issue of client satisfaction and public relations, is the separate concern that outfitters and guides have for a potential liability claim as the result of a client's injury. It seems logical that the prudent outfitter or guide would purchase liability insurance for protection against a possible court judgement resulting from the outfitter or guide's negligence. With appropriate liability insurance coverage, the outfitter or guide's insurance company would go to court on behalf of the outfitter or guide or pursue the route of a negotiated settlement of the claim, depending upon the circumstances surrounding the injury. In any event, the outfitter or guide is "protected" from financial loss in the event of such a suit. Defense costs alone, even if an outfitter or guide wins a lawsuit, could exceed $\$ 25,000.00$. Therefore, the value of liability insurance to a prudent businessperson should not be underestimated. 
However, coverage by liability insurance is not the only means of risk management protection that should concern wildemess outfitters and guides. If an injury occurs to a client, having liability insurance protection is critical as described above due to the potentially overwhelming costs. Foreseeable injuries must be prevented by sound planning. It would be unrealistic to expect an outfitter or guide to protect clients from all possible sources of injury. Indeed, some injuries are unpredictable and consequently unforeseeable. However, if an injury is foreseeable, then allowing the injury to occur to a client, when one owes a duty to reasonably protect from harm, is unreasonable.

It was, therefore, the purpose of this study to investigate the nature of liability insurance coverage and other risk management behaviors among wilderness outfitters and guides in North America to determine the degree to which wilderness outfitters and guides are attempting to reduce their likelihood of being sued by a client and, if sued, to be personally protected from the financial result of an adverse verdict.

\section{EETHODOLOGY}

Subjects were 42 wilderness outfitters and guides in North America (28 Americans and 14 Canadians). The subjects ranged in age from 27 to 60 , with an average age of 39 . Thirty-four subjects were male, 5 were female, and 3 were unidentified. The subjects' years of experience ranged from 2 to 41 years, with an average of 15 years. Twenty-six of the 42 outfitters and guides maintained yearround, full-time operations. Twelve others operated seasonal, full-time businesses. The peak season for 33 of the subjects was summer. Various licenses and certifications were possessed by 35 of the subjects. The subjects selected for this study resided in 14 states and 5 provinces.

As a result of studying the literature conceming risk management planning in physical activity settings (Adams, Adrian, \& Bayless, 1987; Baley \& Mathews, 1989; Dougherty, 1987; Koehler, 1988; Riffer, 1985), the author created a survey designed to address various elements pertaining to liability insurance and other risk management behaviors related to wilderness outfitting and guiding.

\section{RESULTS AND DISCUSSION}

While almost all of the American subjects carried liability insurance (one chose not to obtain it and one was unable to obtain it), $40 \%$ of the Canadian subjects were not covered by liability insurance (two chose not to obtain it and two were unable to obtain it). The most common liability insurance coverage limit for American subjects was $\$ 500,000$., but for Canadian subjects it was $\$ 1,000,000$. No Canadian subjects reported purchasing liability insurance at an amount less than $\$ 1,000,000$. There was a higher percentage of Canadian subjects than American subjects who did not carry other forms of insurance related to their businesses, such as business auto, property, equipment, disability, business interruption, theft, etc.

American subjects indicated a slight increase in current year liability insurance rates over the previous year while Canadian subjects indicated a slight decrease in premiums paid. Even though American subjects tended to purchase lower coverages of liability insurance than did the Canadian subjects, the American subjects paid considerably more for their coverage than did the Canadian subjects. Among 
all subjects, $42.3 \%$ experienced a rate increase in premium paid for liability insurance for the current year over the previous year. Although some subjects indicated that the nature of their liability insurance coverage had changed (37.5\%), most indicated that they had made no changes in their coverage when compared to the previous year. Such changes included increased/decreased limits, no coverage the previous year, increased/decreased deductibles, and increased/decreased activities covered.

Although slightly over one-third of the subjects indicated that they had, at least on one occasion, been refused liability insurance, the incidence of refusal occurred at a higher rate for Canadian subjects. Most subjects indicated at least some degree of difficulty in obtaining appropriate liability insurance coverage. In fact, almost $60 \%$ of the subjects indicated average difficulty or greater in successfully obtaining liability insurance. There was a substantial number of subjects ( $40 \%)$ who indicated that they planned to make changes in the nature of their liability insurance coverage at the next anniversary date of their policy. This desire was far more common among American subjects. Such changes included trying to locate the same coverage for less money, changing companies, increasing limits, increasing deductibles, soliciting more bids, and adding coverage for new activities.

From the data collected, it appears that concerns over potential liability and liability insurance coverage have affected programs and services offered by the wilderness outfitters and guides surveyed. In fact, $40 \%$ of the subjects indicated that they have made changes in the manner in which they conduct their services and programs due to such concerns. Table 1 describes the program changes identified by the subjects in response to an open-ended question. Changes made in such services should benefit the recipients of those services - the clients (with the exception of the one change related to increased costs).

Table 1: Changes in the Services and Programs Offered Due to Concerns Over Liability Insurance Coverage

1. Became more cautious with equipment rentals.

2. Became more cautious with information given to clients.

3. Started using waivers.

4. Started completing injury report forms.

5. Increased the costs of services and programs.

6. Created tighter vehicle operating procedures.

7. Offered better and safer instruction to clients.

8. Started a formal safety program.

9. Started monthly in-service staff meetings.

10. Created an employee handbook with written safety policies.

11. Began basing all decisions on potential liability. Employees are trained in decision-making to ask, "How would this sound in court?" 
The same concern that has led to improved program changes has also led to the elimination of some programs and services. The data indicated that $28.6 \%$ of the subjects have eliminated program or services due to their concerns related to potential liability and their liability insurance coverage. Table 2 describes the types of programs and services that have been eliminated as identified by the subjects in response to an open-ended question. The data indicate that seven of the services identified were on-water activities, three of which involved kayaks. Two services involved the use of animals - dogs and horses. Additionally, two other services (rock climbing and sheer cliff diving) appear to be somewhat high risk in nature, as are whitewater kayaking and open ocean kayaking.

Table 2: Services and Programs Eliminated Due to Concerns Over Potential Liability and Liability Insurance Coverage

1. Eliminated dog-sledding because of question of competence of handlers.

2. Eliminated canoe instruction course because liability insurance costs were greater than course income.

3. Eliminated snowmobile rentals.

4. Eliminated horseback riding and horseback trips.

5. Eliminated whitewater kayak rentals.

6. Eliminated some whitewater kayak trips.

7. Eliminated open ocean kayak touring.

8. Eliminated rock climbing.

9. Eliminated sheer cliff diving.

10. Eliminated water skiing.

11. Removed diving board from swim raft.

12. Removed playground equipment.

13. Eliminated some guide service.

14. Eliminated liquor service.

15. Removed oral medicines from first aid kits.

Table 3 describes the data most closely related to the actual occurrence of lawsuits and the result of those lawsuits. Only $7 \%$ of the subjects had actually been sued. These three subjects accounted for only four suits among all 42 subjects surveyed. All three of the subjects were Americans; none of the Canadian respondents had ever been sued. These four cases resulted in two settlements, one suit dropped, and one suit currently in litigation. Therefore, the data in this study failed to reveal any jury decisions against an outfitter or guide who responded to the survey. 
Table 3: Subjects' Liability History

Descriptor

Ever been sued

Yes
No
$\%$ sued

* 2 subjects sued once; 1 subject sued twice
American

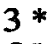

25

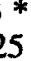

$7 \%$
Canadian

0

14

Results of lawsuits

Now in litigation

Settled out of court

Suits dropped

Judgement for/against

Financial result of settlements
Disclosed
1 ( $\$ 20,000$. broken ankle)
Undisclosed
1 (no insurance)

Table 4 shows the subjects' responses to the two survey items related to the use of waivers and indemnification agreements. Although $88 \%$ of the subjects required their clients to sign waivers prior to participation, the substance in the waivers varied considerably. Many subjects attached a copy of their waiver(s) to the survey as requested. Essentially, some waivers were relatively simple where the client acknowledges that there is a degree of risk involved in outdoor advebture activities and the client agrees to accept responsibility for injuries sustained as a result of participation. On the other hand, some of the waivers were much more extensive and explicit where specific risks were identified and relevant rules were explained to the clients. Other typical areas addressed by the various waivers included: an acknowledgement that the client is in good health, details related to possible injuries, an agreement to abide by the guide's instructions, and an agreement not to consume alcohol while paddling on the river.

Table 4: Use of Waivers and Indemnification Agreements

Descriptor

Require users to sign waivers

$$
\text { Yes }
$$

No

$\%$ yes
American

26

2

$88 \%$

Require users to sign indemnification agreements

Yes
No
Missing
$\%$ yes

$15-5$

129

\% yes

$49 \%$ 
Many subjects indicated that they used the same waiver for all activities while other subjects indicated that they had different waivers for different parts of their program. Additionally, some subjects noted that their waiver was provided to them by their insurance company while other subjects indicated that they had hired an attorney to write their waiver. Several subjects wrote on their surveys that they were not exactly certain of the legal value of their waiver, but they felt that the waiver might grasp the attention of clients regarding the seriousness with which they should consider the possibility of injury. Others noted that they felt the waiver might deter some lawsuits. One subject indicated on his or her survey that, as part of the indemnification agreement, the client agrees to pay the costs of any rescue or emergency evacuation necessitated by an accident.

In regard to the survey item concerning relevant certifications and licenses, the subjects generated an extensive list of credentials. Many of the subjects indicated that they possessed certification or licensure from their particular state or province. Skill-related certifications included those related to first aid, cardiopulmonary resuscitation (CPR), lifesaving, emergency medical technician (EMT), canoeing instruction, whitewater instruction, coastal kayaking, swift water rescue, and ocean lifesaving.

Many of the subjects indicated that their certifications were at the instructor level rather than at lower levels (e.g. first aid instructor rather than just first aid certification). By obtaining various certifications, including advanced levels, pertaining to the outfitter/guide industry, the subjects should be better prepared to prevent and competently manage possible injuries sustained by their clients. Professional preparation cannot be overemphasized in its role within a sound risk management program.

Perhaps the most significant results of this study were related to determining current risk management/injury prevention strategies that outfitters and guides were actually performing to decrease the likelihood of unreasonable injuries and resulting lawsuits. The responses to the open-ended survey item related to actual risk management/injury prevention strategies can be grouped into four major categories: (1) staffing and training, (2) equipment, (3) written planning and documentation, and (4) organization of programs and services. Tables 5 through 8 list detailed examples of risk management behaviors from each of these four categories as identified by the subjects in this study.

Table 5: Risk Management//njury Prevention Strategies:

(1) Staffing and Training

1. Hiring only highly qualified staff.

2. Hiring only experienced staff (e.g. 3 years minimum experience with company before independent guiding).

3. Providing expert instruction to clients.

4. Maintaining low client-to-employee ratio (e.g. 5 to 1 ).

5. Ensuring that staff maintains all relevant certifications (e.g. first, $C P R$, EMT, etc.).

6. Developing an on-going staff in-service training program (e.g. discussing real problems and proposing effective solutions, practicing critical skills, etc.). 


\section{(Table 5 cont'd)}

7. Practicing written crisis management plan (i.e. emergency evacuation of client with severe injuries).

8. Providing personal, close supervision of employees to assure compliance with company policies and procedures.

9. Holding pre-trip discussions to plan and holding post-trip discussions to assess potential problems related to safety.

Table 6: Risk Management/Injury Prevention Strategies: (2) Equipment

1. Purchasing and using the best equipment available on the market.

2. Maintaining equipment in excellent condition by performing preventive maintenance.

3. Training clients how to use the equipment properly prior to trips.

4. Providing expert supervision by employees while clients use equipment.

5. Ensuring that equipment is properly fitted for effective use by clients (e.g. proper fitting of personal flotation devices).

6. Inspecting equipment regularly.

7. Performing preventive and corrective maintenance for equipment.

8. Developing standards for use and rental of equipment that are beyond the minimum allowable (e.g. no seat cushions used as personal flotation devices).

Table 7: Risk Management/Injury Prevention Strategies: (3) Written Planning and Documentation

1. Establishing specific, written standards and procedures for hiring competent staff.

2. Developing an employee handbook with detailed policies and operating procedures.

3. Developing and practicing written safety policies for staff training (e.g. written crisis management plan with detailed emergency evacuation procedures).

4. Conducting written employee evaluations based upon job-relevant criteria.

5. Utilizing peer evaluations conducted by other outfitters/guides.

6. Informing clients in writing of the inherent risks related to the program/ activity, followed by a well-written waiver.

7. Completing detailed, written accident/injury report forms.

8. Posting appropriate signage and rules.

Table 8: Risk Management/Injury Prevention Strategies: (4) Organization of Programs and Services

1. Planning low risk expeditions.

2. Stressing conservative risk-taking. 


\section{(Table 8 cont'd)}

3. Providing excellent client supervision on trips.

4. Following every safety precaution known in the industry.

5. Providing clients with detailed, quality pre-trip information and instruction.

6. Requiring mandatory safety instruction for first time renters of equipment.

7. Screening clients selectively.

8. Talking about and stressing safety in all activities (i.e. "Safety first; pleasure follows").

9. Basing all decisions on the potential likelihood of injury and possible liability.

10. Avoiding travel in foul weather.

11. Stressing constantly: common sense, good judgement, and great care.

\section{E IMPLICATIONS FOR PRACTITIONERS}

Although the data collected in this study indicate that many wilderness outfitters and guides were performing prudent risk management behaviors in an attempt to reduce the likelihood of unnecessary injuries to clients (Tables 5-8), it must be recognized that not all subjects reported performing all of the behaviors discussed in this article. In other words, although almost every subject indicated that he or she was performing one or more of the risk management behaviors described in Tables 5-8, no subject was performing all of the behaviors. It is perhaps obvious that this would, in many cases, be almost impossible, if not impractical. However, since the goal of each wilderness outfitter and guide should be to prevent unreasonable injuries to their clients and therefore avoid unwanted claims of negligence, then it is important for each wilderness outfitter and guide to make a concerted effort to perform consistently each of the identified risk management behaviors that are appropriate for a given situation. The best way to ensure that this will occur is to develop a written risk management plan.

Each wilderness outfitter and guide should identify those behaviors, policies, procedures, and practices that are most closely related to preventing unreasonable injuries in the respective programs and services offered. The risk management behaviors identified in this article could serve as a starting point for such a plan, but it is entirely possible that a given outfitter or guide and his or her

staff could generate many more risk management behaviors specifically developed for the programs and services that they offer. When this type of foresight is demonstrated through a structured planning effort, it is very likely that prudent risk management behaviors can be identified and implemented, thus increasing the likelihood of preventing unreasonable injuries to clients. As a result, programs can become "safer", negligence claims can be reduced, and clients can successfully enjoy the services offered by the various outfitters and guides.

Truly "safe" programs do not just develop by chance. They occur as the result of carefully planned activities and services that have been structured with reasonable foresight. A poorly planned program might exist for a certain time with few injuries and no negligence claims; however, the likelihood that this successful record will continue for an extended period of time is slim. Obviously, even a well- 
planned program can encounter injuries, but the goals of a sound risk management plan are to take every reasonable step to reduce the likelihood of injuries, to reduce the severity of injuries that do occur, and to reduce the likelihood of a negligence claim arising from injuries that do occur.

\section{References}

Adams, S., Adrian, M., \& Bayless, M. A. (Eds.). (1987). Catastrophic inuries in sports: Avoidance strategies. Indianapolis, IN: Benchmark Press, Inc.

Baley, J. A., \& Matthews, D. L. (1989). Law and liability in athletics, physical education, and recreation. Dubuque, IA: Wm. C. Brown.

Dougherty, N. J. (Ed.). (1987). Principles of safety in physical education and sport. Reston, VA: AAHPERD.

Koehler, R. W. (1988). Law: Sport activity and risk management. Champaign, IL: Stipes Publishing Co.

Riffer, J. K. (1985). Sports and recreational injuries. Colorado Springs, CO: Shepard's/McGraw-Hill. 